\title{
The quality of live of patients' allegic rhinitis after posterior nasal neurectomy at Dr Sardjito General Hospital Yogyakarta, Indonesia 2016
}

\author{
Wahyu Dwi Kusdaryanto*, Windarti Isminarsih, Luh Putu Lusy Indrawati \\ Otorhinolaryngology Head and Neck Surgery Department Medical Faculty ofUniversitas \\ Gadjah Mada/ Dr. Sardjito General Hospital Yogyakarta, Indonesia
}

DOI: http://dx.doi.org/10.19106/JMedScieSup0050012018014

\section{ABSTRACT}

Allergic rhinitis (AR) is disease by incidence, high prevalence, and expects to rise to load against the economy and lowering the quality of life of patients. AR involved many factors. It is an impact of highly significant on the quality of life and affects the economy. The patients' life quality was done to assess the effects and result of surgery. Sino nasal outcome test -20 (snot-20) was one of the instruments specific measurement of AR patient's live quality. Total of 10 patients who surgery action, obtained improving the quality of life based on snot-20 observed 28 days after done the act of surgery. Rate the SNOT-20 before surgically obtained 37.3 with DS \pm 7.87 and 28 days after done surgically obtained mean snot-20 was 6 with DS \pm 2.49 . The SNOT-20 pre and post action were different of significant $(p=0.024)$.

Keywords: allergic rhinitis - SNOT-20 - posterior nasal neurectomy

*corresponding author: wahyukusdaryanto@gmail.com 